\title{
Integration of Digital Technologies into Underground Utility Asset Management
}

\author{
Eronmonsele Esekhaigbe, Emrah Kazan*, Mumtaz Usmen \\ Department of Civil \& Environmental Engineering, Wayne State University, Detroit, USA \\ Email: *ekazan@wayne.edu
}

How to cite this paper: Esekhaigbe, E., Kazan, E. and Usmen, M. (2020) Integration of Digital Technologies into Underground Utility Asset Management. Open Journal of Civil Engineering, 10, 403-428. https://doi.org/10.4236/ojce.2020.104030

Received: December 1, 2020

Accepted: December 28, 2020

Published: December 31, 2020

Copyright $\odot 2020$ by author(s) and Scientific Research Publishing Inc. This work is licensed under the Creative Commons Attribution International License (CC BY 4.0).

http://creativecommons.org/licenses/by/4.0/

\begin{abstract}
Installation, detection, maintenance, mapping, and management of underground utility assets present challenges to owners, engineers and contractors. Industry-wide practices include the use of geophysical and similar technologies to determine depth and location, and $2 \mathrm{D}$ as-built plans integrated with GIS databases for information management. The feasibility of incorporating 3D BIM models of the subsurface to replace the 2D plans to improve visualization and data management is examined in this paper. Obtaining an accurate image of the underground infrastructure would help minimize excavation accidents due to equipment-utility collisions and prevent property damage. Further, the inclusion of automated data collection and sharing features realized through BIM technology can enhance operations of smart cities. The research methodology consists of a state-of-the-art review of the current underground utility management systems, combined with statistical analysis of survey responses received from utility providers and one-call centers in the U.S. Three categories of utility practices are identified based on the level of digital technology integration. It is found that a vast majority of utility firms have adopted GIS databases with 2D plans, depth and other asset information, while a smaller percentage of providers have achieved full GIS-BIM integration, incorporating a wide range of asset data. Future progress on broader implementation appears to be constrained by the digital literacy of personnel and high costs of technology acquisition and application. A three-step framework for converting 2D plans to 3D BIM models is also presented and discussed. The process model proposed for this purpose allows the utilization of commercially available software with minimal need for additional coding.
\end{abstract}

\section{Keywords}

Underground Utilities, Asset Management, Digital Technologies, GIS Database, 3D BIM Model 


\section{Introduction}

The feasibility of incorporating 3D BIM models of the subsurface to replace the $2 \mathrm{D}$ plans to improve visualization and data management is examined in this paper. Achieving this objective will also improve safety of excavations associated with underground utility locating and mapping while preventing property damage. In addition, the connectivity features established through the integration of digital technologies would be expected to play a beneficial role in the operations of future smart cities.

The underground infrastructure, especially in urban centers, is comprised of a complex network of utilities encompassing electric, gas, and telephone lines, fiber optic and television cables, water mains, and sewerage pipes, and other assets such as street lighting circuits, drainage systems, and flood control facilities. There are over 35 million miles of buried service utilities in the United States, and with continuing urbanization, this network is constantly being expanded and upgraded to accommodate the growing population and the ever-changing societal needs [1]. Accurate determination, recording, and management of key information (location and attributes) pertaining to this vast infrastructure network often present challenges because of the difficulty of direct physical access to the underground and the elevated costs of establishing and maintaining an up-to-date database. The problem is exacerbated by the presence of abandoned utilities that might have been installed in the ground many decades ago, for which records may be incomplete or absent. In contemporary practice, as-built plans of the active underground networks are most frequently represented by $2 \mathrm{D}$ CAD drawings; however, when depth information is lacking or inaccurate, the value of the drawings becomes questionable. Changes in topography due to new construction, renovation and maintenance, ground erosion, along with the limitations of the detection equipment and human errors in locating the utilities, compromise the accuracy of mapping the underground space [2].

An important concern arising from the uncertainties around the type, position, and configuration of subsurface assets is the possibility of collisions between the excavation equipment and buried utilities. It is known that accidents causing injury or fatality to workers and site personnel occur due to explosions and electrocutions while the ground is being excavated to install utilities. These mishaps also cause property damage, decrease excavation productivity, and disrupt essential services to the consumers. In the absence of reliable geospatial data, the chances are real for such accidents [3].

Recently, there has been interest keeping the subsurface utility asset data and information in the form of $3 \mathrm{D}$ models that include depth measurements. With the advent of the Building Information Modeling (BIM) tools, incorporating such data in the operation of smart cities has shown rising potential. Besides improving the visualization of the underground utility networks, the inclusion of accurate asset information in an intelligent database could digitally connect all parts of buildings, bridges, and other infrastructures to bring the communities 
closer to the realization of a well-functioning smart city. The use of 3D BIM models representing the underground landscape as a digital twin will be an essential element of this enterprise. As described by Mohanty et al. [4] and Patel et al. [5], a smart city is one that connects the physical, information technology, and social and business infrastructures to leverage the collective intelligence of the city, where all components are digitalized, continually updated, and integrated into a single database, leveraging the full capacity of the Internet of Things (IoT). US cities like Boulder, Pittsburgh, San Francisco, Louisville, Fresno, LaGrange, Columbus, Austin, Cedar Rapids, and New York have made considerable progress towards achieving the goal of becoming smart cities [6].

In the next section of this paper, we present the research scope and methodology, followed by sections covering the state-of-the-art review, collection and analysis of survey data, main findings, discussion and conclusions.

\section{Research Scope and Methodology}

The study reported herein was exploratory in nature, and aimed to address the following research questions:

- What are the general practices for underground utility installation, location, tracking, and information management?

- What are the nature and extent of the problems and challenges associated with the detection and placement of underground utilities?

- What are the digital tools and technologies employed to support underground asset management systems?

- What is the extent of digitalization of the subsurface asset management practices currently adopted by the utility industry, and what are the expected future trends?

- Are there feasible approaches to converting 2D as-built plans to 3D BIM models to improve the visualization of the underground space that would increase accuracy of the locates and minimize excavation accidents and utility damages, while providing for efficient database management?

A state-of-the-art review was conducted first to examine the issues embedded in these questions by surveying the pertinent literature. This task was supplemented and reinforced by personal contacts and communications with various industry practitioners. Representatives of utility companies, design and construction firms, technology proprietors, and utility notification agencies (one-call centers) comprised this group. In addition, two survey questionnaires were designed to gain insights into the current state of practices related to the implementation of digital technologies enabling 2D/3D representation and management of the underground utilities. In parallel, an effort was made to identify the present drivers and future challenges of digital transformation in the utility industry. One of the surveys was distributed to utility company representatives, and the other one to the professionals working for one-call centers. The survey was administered using Qualtrics software. Microsoft Excel was used to organize 
the data collected from the respondents, and the data was analyzed employing the Statistical Package for Social Sciences (SPSS) running univariate frequency analyses. Additional information acquired through interviews via phone calls, emails, and face-to-face meetings reinforced the results obtained from the survey.

\section{State-of-the-Art Review}

\subsection{Installation and Maintenance of Underground Utilities}

Underground utilities are owned by public or private utility firms in the US, which conduct business in designated regions. These firms maintain extensive records of their underground assets, which must be effectively managed for safe and cost-effective operations. This information is kept in databases consisting of $2 \mathrm{D}$ as-built plans with or without depth and other attribute information (e.g. maintenance records), or less frequently in $3 \mathrm{D}$ digital models that represent the underground space and assets. The end-users of the utility services are the owners of public or private facilities including hospitals, factories, schools, farms, residential homes, and building complexes that need water, wastewater, gas, electric, and telecommunications services.

According to Zeiss [3], an estimated 10 billion dollars are devoted annually to locating subsurface utilities in the US. For any project requiring excavation work, the property owners, or their surveyors, designers, or contractors, must notify the one-call center in the particular state to request that the underground utilities in the area of interest be located. The one-call centers are non-profit agencies operating in a state that serve as a connection between the excavating contractors and the utility companies that own the underground utility assets. Examples of one-call centers include MISSDIG in Michigan, Bud-Call before You Dig in California, Georgia811, and Miss Utility in Kentucky. Individual utility providers must have a mandatory membership with the one-call center designated for their state. It is expected that each utility firm has a map and database of its utility lines, also known as the member polygon. By law, one-call centers must be notified before any excavation activity is commenced regardless of the state, and they can be reached by dialing 811 . The locate task is typically completed within 3 business days [7].

Procedurally, a ticket is created by the contractor, homeowner, or designer to activate the services of the one-call center, which forwards it to the appropriate utility firms that have the member polygons applicable to the proposed excavation site. This will prompt the utility providers servicing the specific area to dispatch a team for marking out the location and path of their underground lines using paint and/or flags. Utility marking flags are based on a color-coding system that is established by the American Public Works Association (APWA) with different colors signifying different types of utility. A "tolerance zone", usually set by the one-call center around the utility for added safety, requires hand digging near the marked line [8]. There are private firms offering utility location 
services using GPR or other detection methods. Finally, it is important to note that every state has a regulatory body that ensures the safe delivery of services at a reasonable cost. The Public Service Commission established in Michigan is an example of such an entity.

\subsection{Safety and Property Damage Concerns}

A critical hazard of ground excavation is the risk of inadvertently hitting a part of the underground infrastructure. According to the latest Damage Information Reporting Tool [9], the estimated total number of damage cases in North America for 2018, including near misses, was 440,749. According to this report, both the total damages and the damage reduction per dollar of construction (a measure of cost effectiveness) had plateaued out, meaning that concerted efforts are needed to improve upon this situation. Various factors impacting current damage prevention efforts were identified in the report; namely, increased construction spending, extended construction seasons, fiber-to-the-premises and 5G installations, labor shortages, infrastructure replacement programs, population increase, and GDP growth. It was anticipated that these trends were likely to continue for the foreseeable future. The top four root causes for the occurrence of damages were listed as failing to notify the one-call center/811 (26\%); improper excavation practices (15\%); excavator digging prior to verifying markings (13\%), and excavator digging before valid start day and/or time (11\%), which highlight the importance of accurate locates. In this vein, according to Narain [10], ninety percent of construction projects experience delays, and more than half of these delays stem from uncertainties in the subsurface. It is also important to know that changes due to rehabilitation and repurposing of some facilities, related demolitions, roadway route relocations, and other site factors may alter the orientation and condition of the underground infrastructure, compounding the issue of locate accuracy. Based on the findings of a study in North Carolina, Al-Bayati and Panzer [11] pointed out that the accuracy, as well as timeliness of locates, are very important for damage prevention. The factors affecting late and/or inaccurate locates were determined to be lack of time (number of tickets and seasonal fluctuations); shortages of experienced and trained staff; and poor communications, i.e. working with incorrect ticket type or information. The size of the area assigned to the locator and inclement weather were identified as additional factors impacting accuracy.

Tuttman [12] described a case where a 6-inch underground gas main was damaged during interstate roadway construction on a site with multiple contractors. The investigation revealed improper/inaccurate mark-outs for the underground utility and errors in excavation procedures by a particular contractor. Further, the 2D as-built plan used did not have sufficient information and failed to give a detailed location for the utility lines. It was confirmed that inaccuracy and uncertainty of the utility location was the major cause of the mishap, with the recognition that good geospatial information about the location of utilities, 
excavation accidents, as well as utility damages, could be reduced.

\subsection{Mapping and Visualization of Underground Utilities}

Accurate mapping of underground utilities and infrastructure is an important challenge to the construction industry, as well as mining, oil, and gas, and agriculture sectors [13]. Besides the drilling, sampling, and testing approach, a variety of geophysical methods are deployed for exploring the subsurface profile. However, while these methods generally produce accurate data on the horizontal path and length of the utilities in most cases, improvements are still needed in accurate determination of depth and vertical separation distance of underground objects.

A host of non-destructive technologies has emerged over time for subsurface exploration to locate utilities and other buried objects. The geophysical surveying methods used for this purpose have been reviewed by Talmaki et al. [14] covering features, working principles, and advantages and limitations of various technologies. Ground-penetrating radar (GPR), electromagnetic and magnetometer techniques, resistivity methods, and infrared thermography are among the best-known methods, while potholing, with application of vacuum excavation, is commonly preferred for obtaining visual verification of subsurface utilities and obstructions. The authors acknowledge that no single technology stands out as the most effective because different techniques work better in certain environments than others, and therefore, a combination of these techniques should be used for best results. A more detailed treatise on subsurface explorations for utility location can be found in Read and Vickridge [15].

The position and configuration of subsurface utilities are generally represented by $2 \mathrm{D}$ as-built drawings that are stored by the utility firms. When possible, depth measurements obtained by geophysical methods or other techniques are added to these maps, and many utility firms have taken the next step to integrate this data with a Geographic Information Systems (GIS) database, which may also contain various attribute information about the utilities. The ultimate goal would be the creation of a 3D map as a virtual model, or digital twin, of the subsurface web. This approach can lend itself to the collection of real-world information about the contents of the underground via sensors, drones, and other wireless technologies. The model has the ability to continuously learn from multiple sources, including advanced analytics, machine learning and artificial intelligence (AI) to track performance, while rendering decision support for asset maintenance and modification planning [16] [17].

Reality capture is the process of scanning an object above or below the ground to produce a 3D digital model representing the space; the technique allows capturing site data quickly and accurately and connects it directly to digital design process [18]. This can be achieved by a digital camera, slide scanner, or laser scanner, supported by $3 \mathrm{D}$ rendering software. Another vital component of the system is an automatic identification and data collection tool, such as RFID (ra- 
dio frequency identification), which senses pertinent location and geometric information from the buried pipes and other assets. Geotagging utilities using RFID during installation and storing the relevant information in a database with a 3D BIM model would enrich and improve the underground asset management practice, especially if an accurate depth value may be included. The use of GPS (geographic positioning system) augmented excavation equipment can offer significant help, and once the geolocation is properly imputed to the system, it can be extracted and mapped [19].

Image processing has great advantages and it can be a powerful tool since the resultant digitized, 2D array format can be processed freely to provide information about the size, shape, and location of objects of interest [20]. Digital camera applications combined with virtual reality (VR) or augmented reality (AR) equipment and software can enable tracking site safety practices, document transfer, onsite supervision, and connected infrastructure; however, applications for the visualization of the underground are still not fully developed. Unlike detecting objects above the surface, survey of underground objects requires sophisticated equipment that can scan through a range of materials deep down in the ground. In reality, the harsh propagation environment composed of soil, rock, water, and void spaces does not allow the use of a single communication technology for data transfer between the surface and the underground objects [21]. It is expected that overcoming this obstacle by successfully digitalizing underground infrastructure networks will bolster visualization and systems controls, forming a natural path to the implementation of the Internet of Things (IoT).

\subsection{Internet of Things and Smart Underground Infrastructure}

IoT refers to a digital system of interrelated, internet-connected objects that collect and transfer data over a wireless network without human intervention. It is based on stipulated protocols through sensing equipment to conduct information exchange and communications to achieve smart recognitions, positioning, tracking, monitoring, and administration [5]. To achieve a smart underground infrastructure, it is essential to develop and integrate a 3D BIM model of the underground utilities, supported by IoT sensors (i.e. RFID combined with GPS technology), with geospatial data about the utilities. This model can then be connected to a GIS database to store, organize, retrieve, manipulate, and manage desired information. The Internet of Underground Things (IoUT), introduced by Saeed et al. [21], is similar to IoT but it focuses on underground connectivity. As an enabling technology it has been applicable to smart oil, gas and agricultural fields, and smart seismic control; so, it should be possible to extend it to utilities. However, IoUT implementation is fairly new and faces barriers like high energy consumption leading to faster battery depletion.

The use of digital twins is continually expanding through rapid developments in connectivity through IoT [17]. The utility industry appears poised to transform from 2D as-built blueprints to 3D BIM models, and some utility firms are 
currently planning to create $3 \mathrm{D}$ digital models of underground utilities that can be stored in a GIS database. According to the Environmental Systems Research Institute (ESRI), intelligent GIS maps are being developed with databases that include numeric and textual files (e.g. pdf) from 2D drawings and 3D BIM models [22]. GIS databases improve communications between different stakeholders, and they enable professionals from different disciplines to easily work with the information retrieved from the maps. This facilitates better decision-making by using specific information about the project environment, such as more precise locations of buildings, roads, and underground infrastructure. The result is higher operational efficiency with savings of cost and time.

RFID barcodes attached to underground utilities combined with GPS technology can play a key role in information-based subsurface solutions. The RFID tags contain an integrated circuit and an antenna, which transmit data to a reader. The information thus collected from the tags is transferred through a communications interface to a host computer system, where the data can be stored in a database and analyzed at a later time. An important advantage of RFID tagging over other barcode-based asset tracking systems is that the data can be read outside the line of sight, without using an optical scanner [23].

As a part of an integrated smart 3D BIM-GIS database, RFID can be used to monitor and update information about underground utilities as the system remotely detects and locates them. However, RFID is more expensive than the Quick Response (QR) code technology, which does use an optical scanner. QR codes have been successfully implemented for warehouse inventory, site material and equipment management, scheduling, and timekeeping [24], and it may be possible to apply them to locate underground utilities in a fashion similar to RFID. On the other hand, the maximum scanning distance is limited to depths of 1 to 8 inches, and excavating the ground to scan the utility may not be financially and practically feasible in many cases. Suffice it to say that there are issues with both barcode technologies, because existing and abandoned underground utilities cannot be tagged easily without using special materials and methods, as they lie beneath the soil, buildings, roads, and so on. These applications are therefore best suited for new utilities placed in localized areas of streets or open fields. When both technologies are competitively considered, cost/benefit analysis can be performed to select the more cost-effective solution.

GPS is a navigation system that provides continuous positioning and timing information under all weather conditions through receivers that take signals from satellites [25]. For construction applications, GPS can act as a data capturing and monitoring device to track and record the development of field activity, e.g. excavation for utility installation. Currently, there are earth-moving equipment with GPS systems, used for tracking and managing a single equipment or entire fleets [26]. If GPS is integrated with BIM technology, the automation afforded could result in better capturing of data updates and enhancement of project controls. GPS systems are currently equipped with 3D measurement 
tools that improve precision in site surveying while reducing labor costs, since fewer personnel are needed. High-risk areas of construction sites, such as underground power and gas lines, can be accounted for with GPS tracking, which could help form virtual geo-fences around such areas, and can even alarm the workers to proceed with extra caution. Another feature of the GPS systems is obtaining geotagged photos by digital cameras, mobile devices, and software, and syncing the GPS information in the photos to a specific location on the jobsite [27].

Talmaki et al. [14] reported on research at the University of Michigan (UM) on the design and use of a high-accuracy excavator-utility collision avoidance technology incorporating real-time kinematic GPS. Capturing geospatial data pertaining to subsurface utilities, 3D models of buried pipes in the vicinity of an operating excavator were developed, and the models and their attribute information were superimposed over the excavator's workspace using geo-referenced AR technology. This availed the operator and the on-site spotter with information on the location and type of utilities in the area of excavation through visualization. It was also mentioned that a sensor-augmented GIS system could warn the database managers of anomalies encountered during excavation and maintenance.

In a follow-on effort, the UM researchers further developed the georeferenced AR technology focusing on a knowledge-based excavator control system using GPS, angular sensors, and laser catchers for vision. The system, named SmartDig, consists of low-cost off-the-shelf cameras linked together as a network, and a set of QR codes placed at specific locations on the site as well as the machine. The cameras can look at the markers and locate the position of the excavator's arms at any given time. An important issue with this technology was the required one-inch accuracy, which is difficult to attain when using inexpensive cameras, although reasonably good initial results were obtained in initial field trials. Additional areas of improvement identified were speed, robustness, working range, and the creation of an AR user interface that will provide the operator with visual guidance on the target subsurface profile and location of buried utilities. The ultimate aim of this effort was reported as achieving completely autonomous excavation with a collision avoidance capability [19].

\subsection{D BIM-GIS Integration for Utility Asset Management}

Building information modeling (BIM) is a relatively recent technology based on working with an object-oriented 3D digital model with attached attribute information about a facility. It allows multiple stakeholders and professionals to collaborate on the planning, design, and construction of a facility using a single 3D BIM model which can also be extended into operation and management, with data accessible to clients [28]. The BIM software employed during design and construction include Autodesk BIM 360, Sketch up, ArchiCAD, and BIMx. An attractive feature of BIM is that it displays the information for a facility through- 
out its lifecycle. BIM technology supports automated data collection and serves as a data sharing and updating tool to track work progress in construction projects. If combined with $\mathrm{AR}, 4 \mathrm{D}$ BIM models could facilitate comparisons of the actual situation on-site with the building's planned appearance (design) at any given time [29]. The main goal of an AR application is associating digital information with real-world objects and spaces with visualization [30]. A limitation of using the AR technology is that poor indoor lighting results in a distorted image, and capturing certain dynamic transient activities, such as scaffolding, formwork, and excavation is not meaningful.

Yan et al. [31] have pointed out that having a reliable 3D digital map of utility networks is the key to understanding the important aspects of the underground space. With a 3D BIM model, a more accurate location of the subsurface utilities can be materialized through better visualization and analysis of the space. This is a major advantage over 2D plans, which represent the subsurface network with just lines that can be mistaken for another element. Otherwise, the lines in the as-built plans might be obsolete at the time of review, or the attribute information in the plans, if present, maybe wrong or incomplete. When BIM is used, the data collected on-site by personal digital assistance (PDA) devices, e.g. smartphones, smart clothing, cameras, HoloLens, and so on, are sent to a cloud-hosted BIM model via the internet, and are continually updated. Subsequent comparisons between the data on the cloud-hosted model and the original model will reveal any discrepancies between the two, which will help assess the accuracy of construction monitored progress and/or of project delays resulting from inaccurate data collection [30].

BIM-GIS integration involves superimposing the GIS database on a BIM model to combine geographical location data with design information for the physical infrastructure. The outcome is a highly detailed and holistic body of information that will successfully support asset management [32]. GIS is a broad field covering geo-visualization-based decision making and geospatial modeling [33]. GIS systems convey data at city, state, regional, and country scales, while BIM typically applies to designing and building a specific facility or infrastructure. The BIM-GIS integration brings different types of essential information about infrastructure and geospatial data together to create an intelligent model for planning and analysis of a project that will allow a better evaluation of the existing site conditions, while producing real-time data that is accessible to stakeholders. This will improve the coordination of the utility location requests and the accuracy of locates.

Autodesk and ESRI have partnered together to develop GIS-BIM integration resulting in the development of the Autodesk Connector software. The objective is to facilitate the flow of data between GIS and Autodesk Infraworks software, as well as Autodesk Civil 3D. The Connector allows infrastructure professionals to import GIS data directly into their design model and use that information to develop a real-world context model of their project [34]. It should be noted that, 
it is possible to create a 3D BIM model integrated with GIS maps by combining different readily available software packages.

Talmaki et al. [14] classified subsurface utility data management practices by creating four scenarios (cases) in the context of avoiding damages to utility lines (e.g. pipes) coming in contact with excavation equipment. Case 1 encompassed the companies that have all their asset data stored in a GIS database. This is a highly desirable scenario because it would be relatively easy and straightforward to create a 3D model of the utility lines. Companies represented by Case 2 were those which had the asset data stored in the form of 2D maps and drawings, either in paper or digital form, but did not go as far as creating an intelligent database. For Case 3, the companies had buried utilities, but were unsure of their exact location. When carrying out repairs and rehabilitation, this situation would require the use of geophysical or other location methods, as well as verification. Case 4 was the scenario for when new utilities needed to be laid with documentation of their location. The use RFID tags, possibly in combination with GPS sensors, would also be envisaged in this case. According to the authors, this is an all-encompassing scenario and is the most advanced. The eventual goal for any case was to produce $3 \mathrm{D}$ representations of the underground utilities and project them in AR.

Cheng and Deng [35] presented a framework that was developed for generating 3D models from $2 \mathrm{D}$ as-built drawings. The process model proposed by the authors consisted of three components, which were the GIS environment, the BIM model, and an integrating engine that linked the two environments together. The initial action taken as part of the modeling effort was combining the $2 \mathrm{D}$ CAD raw data with depth information from site surveys, and performs two quality checks. The proximity check determined if the location of an inspection point was on the utility line within a user-defined offset distance (usually $1.5 \mathrm{ft}$.), while the curved line reconstruction ensured that curves in the CAD drawings could be approximated with a series of connected line segments having a user-defined maximum length (typically $15 \mathrm{ft}$.) After these checks, the 3D model was constructed using the 3D buffering toolbox in ArcGIS by uploading and verifying the depth information. Semantic (attribute) data would finally be added to the model to complete the process. A substantial amount of coding was needed to construct this model, and a case study was used to test the validity and practicality of the system.

\subsection{Large-Scale Applications of Smart Underground Infrastructure}

A number of large-scale underground mapping and database applications are reported in the literature and internet sources. These cases reflect not only the utilization of varying technologies in producing smart systems, but some of them also provide benefit-cost analyses of technology implementation. A detailed description of these case studies is not attempted in this paper; the reader 
is advised to refer to the cited sources for additional information.

On the path to becoming a smart city, Chicago set a vision to generate a digital blueprint of its underground infrastructure network for power cables, gas, water, sewer, wastewater, stormwater pipes, and some other utilities. As summarized by Zeiss [3], the City launched a pilot effort in 2016 to deploy a platform for collecting data and creating and sharing a 3D map of the underground. A new technology developed by the University of Illinois' Real-Time and Automated Monitoring and Control Lab (RAAMAC) and a Chicago start-up firm, City Zenith, was adopted for this purpose. The RAMAC software uses photos captured by inexpensive digital cameras during excavation and builds 3D digital models, which can be securely shared between the City of Chicago and its construction contractors. The advantage of data collection by this approach is that it does not interfere with construction work. According to this reference, a similar system has also been devised by Bentley with smartphones that can be used to create a 3D model of comparable accuracy to a laser scan survey, reportedly at a much lower cost.

The I-20/I-59 Corridor Project in Birmingham, Alabama, with a total cost estimate of $\$ 750$ million, was challenged with utility coordination on an interchange situated in the city's congested business district. Recognizing the complexity of the task, ALDOT decided to develop a 3D model of the utilities located both above and below the ground. Potholing and scanning with GPR augmented the existing as-built records enabling the agency to accurately create a full $3 \mathrm{D}$ model of the underground utilities to share with the contractors who were bidding on the project. Because of the reduced risk afforded with the model relative to the existing underground infrastructure, an estimated cost savings of more than $\$ 10$ million was attained [3].

A mobile mapping platform that captures above the surface and underground data using a photo, laser, and GPR (Leica Pegasus: Stream) technologies was introduced in Singapore, which strives to optimize its underground space because of its scarcity of land. The mapping equipment used was attached to a car moving at $15 \mathrm{~km} / \mathrm{hr}$ to capture data from nine selected areas that were surveyed. An important finding of this study was that no single detection technology was effective for all types of utilities at every location. It was concluded that a range of technologies besides GPR could provide viable solutions for underground utility mapping in terms of detection capability, coverage, efficiency, and accuracy [31].

A highway revitalization project costing $\$ 39$ million was undertaken in Cedar Falls, Iowa. This was a 6-lane road carrying 20,000 vehicles a day which had a crash rate of 20 percent above the state average, with no pedestrian and bicycle lanes, inefficient traffic operations, and a worn-out pavement. A 3D BIM model of the underground utilities was created before the start of the design phase of the project. The BIM model showed the existing roadway, highway features, and the buried utilities beneath the road, extending to the boundaries of the right of way. Drones and mobile scanners were utilized to detect the above surface utility 
assets, and GPR was adopted to map out the subsurface conditions. The reality capture part of the project before designing the highway helped with detection of about 200 utility clashes. This enabled project completion of construction on-time and 3 percent under budget, saving Cedar Falls about \$700,000 [3].

Berntsen International, Inc. has developed a smart solution named InfraMarker, which combines RFID with Ultra High Frequency (UHF) readers, cloud data management services, and geo-locating software to mark, locate, and manage underground assets. This technology was adopted for use in the 58-mile, multibillion-dollar Seattle Sound Transit Light Rail project. Aiming to provide fast, frequent, and reliable connections to riders in the state of Washington, it is scheduled to be completed by 2035. The first phase of the project, known as the E130 East Link, is a 7-mile section running from Seattle to South Bellevue. Having an ambitious target completion date of 2023 drove the project team to find best-practice approaches to safely finding and marking the location of existing underground utility lines prior to reconstruction. With the connectivity of InfraMarker to digitally capture and share project information, information became easily accessible to field operations and asset management personnel. Using potholing equipment and then placing InfraMarker RFID sensors at key location points, the project personnel were able to protect against asset damages by exposing utilities. In addition to depth information, attribute data on utility type, size, installation date, contractor, field technician, and location methodology was collected and stored. Locations were quickly documented with images captured by a mobile phone and kept for subsequent linking with each asset record [9].

The UK government introduced two construction objectives in 2013 which are expected to be achieved by 2025; a 33 percent reduction in the initial cost of building construction and a 50 percent reduction in time for all new buildings, including renovations. Related research established that resources are frequently wasted because of unforeseen events that slow and disrupt the work schedule, causing project delays. It was also determined that scope changes and rework to correct errors in construction increased the initial cost of construction, as well as the estimated time of completion. These findings prompted the Scottish Geotechnical Group (SGG) to evaluate the possibility of integrating geotechnical data with BIM models. Based on responses to survey questionnaires, and a case study analysis on an embankment stabilization project for a former coastal trunk road, the study formed a strong consensus on the merits of integrating geotechnical data with the BIM process. During the excavation of the drainage area, several conventional service utilities, as well as archeological artifacts were found underground, and this caused changes in scope, schedule delays, and cost escalation. Survey respondents identified soil strength parameters, soil bearing capacity, and soil stratigraphy as the important information needed on the subsurface for civil engineering projects; however, they never mentioned underground utilities, old/abandoned structures, or other subsurface conditions (e.g. water table). 
Tawelian et al. [36] who reported on this case study indicated that more detailed information covering such features would have led to improvements in planning, designing, and constructing a leaner project.

Lastly, Zeiss [3] informs that the Netherlands government has recently embarked on a national program supported by a new law that initiated a Key Registry for the Subsurface, Basisregistratie Ondergrond (BRO), which is open and accessible to all citizens of the country. The law mandates that beginning in 2018 anyone who excavates, or drills has to share the data (relating to soils, geotechnics, and groundwater) with the BRO registry. Also, when using the data in the registry, if something is found to be incorrect it must be reported. New standards for recording data will be required, and there is a major effort underway in the Netherlands to develop these standards. According to the report, this registry is an important first step in the process of developing models of the subsurface that can be joined seamlessly with above-ground information to create the comprehensive digital twins that will be used by the smart cities of the future.

\subsection{Relevance of Current Research}

Published information on installation, maintenance, mapping and visualization of underground utilities, excavation safety and property damage concerns, concepts of Internet of Things and smart underground infrastructure, 3D BIM-GIS integration for utility asset management, and the limited large-scale applications of smart underground infrastructure have been reviewed in the forgoing sections of this paper. It is observed that although valuable information has been disseminated through these sources, technology integration into subsurface infrastructure management is still a developing frontier. The research presented here synthesizes the existing knowledge of this realm and aims to further it by analyzing and categorizing the relevant industry practices, followed by modeling the integration processes incorporating digital tools.

\section{Research Survey}

The main purpose of the survey effort in this research was to gain insights into and evaluate the current practices for managing the underground utility assets, with emphasis on improving information management, site safety, and utility damage prevention. A secondary goal was to gather information on perspectives from industry practitioners on future trends and impending challenges associated with desired progress towards creating smart underground infrastructures. Two separate but related survey instruments were designed, and they were distributed to two separate groups; representatives of the utility providers (companies) and the staff of one-call centers.

\subsection{Survey Data Collection}

An overview of the logical sequence for collecting information (responses) from the mentioned groups through survey questionnaires is presented in Figure 1, 


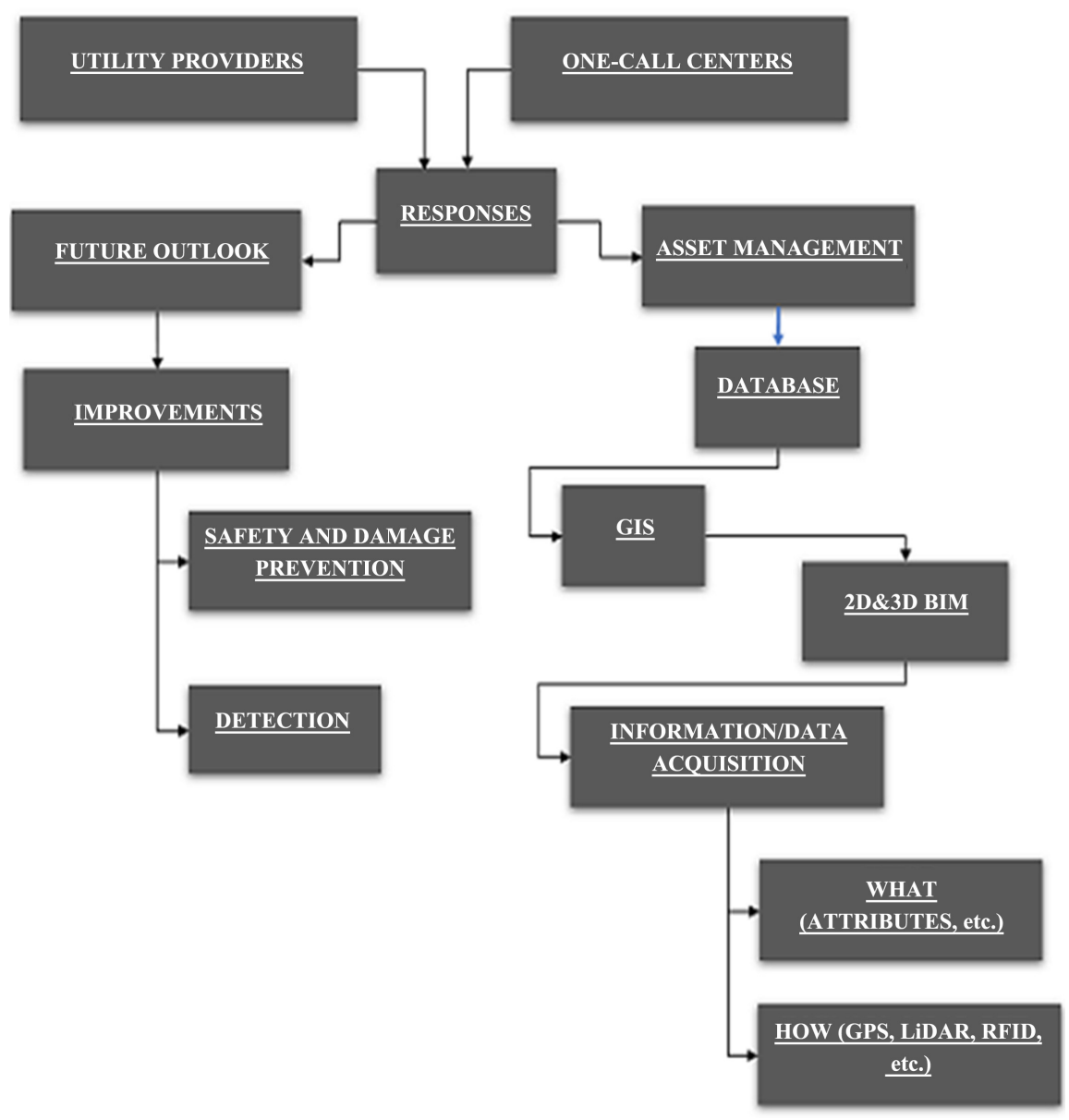

Figure 1. Logic diagram for survey questions.

while the individual questions are listed in Table A1 and Table A2, respectively for utility industry and one-call centers. The tables appear in the Appendix. As seen in these exhibits, our data acquisition effort started with exploring whether the utility companies were conducting any asset management, and if digital tools were used to maintain and track their underground assets, along with the frequency of information updates. The next inquiry was whether the companies had adopted a GIS system to map and manage their asset data within their service areas. A closely aligned question on GIS utilization was also directed to the one-call centers. The utility firms were additionally asked if they were storing their data by using $2 \mathrm{D}$ as-built plans or $3 \mathrm{D}$ models, and the utility providers were probed on the types of data stored in their GIS database along with the technologies adopted for acquiring and tracking data.

Different but related questions were presented to the one-call centers. In addition, both the utility professionals and the one-call center representatives responding to their respective surveys were quizzed on the major causes of the ground excavation safety hazards to round out the objective questions. Subsequently, the survey delved into the use of intelligent 3D BIM models by the utility companies for managing underground utility information, also asking which 
utility detection tools were employed to capture information.

A specific question directed to the utility companies which were not working with an intelligent BIM model was whether they were planning to acquire this capability in the future. Also, their feedback was solicited on the anticipated changes in technology adoption, integration, and deployment for improved data management in the future.

The questions directed to the one-call centers followed a similar logic; however, they were worded differently to account for their dissimilar roles and responsibilities. Besides gathering information on their GIS database ownership, storing 2D plans, and 3D model development, there were several opinion-based questions submitted to this group attempting to elicit information and thoughts on the future outlook to broadly examine what improvements should be realized with respect to the subsurface utility detection methods, and the measures to be taken for excavation safety and prevention of damages. Additionally, the one-call centers were asked whether they verified the utility asset maps (member polygons) uploaded by the utility firms. Finally, the one-call center respondents were requested to express opinions on whether they would consider converting the member polygons to 3D BIM models to improve operations; and if they foresaw any disadvantages to adopting solely the 3D BIM model for subsurface visualization and information management. It is important to note that written comments were solicited from all respondents to elaborate on and/or supplement their answers to survey questions. These comments were noted and integrated with the results obtained from data analysis.

A total of 242 surveys were distributed across the country; 211 to utility industry professionals, receiving 38 returns (18\%), and 31 to one-call centers getting back 8 returns $(25.8 \%)$. Three of the 38 industry responses had missing data, so only 35 (16.6\%) valid survey returns were analyzed. Overall, the State of Michigan produced the highest response rate with 7 responses; other states from which responses were returned were Arkansas, Colorado, Georgia, Illinois, Iowa, Kansas, Maryland, New York, Ohio, Pennsylvania, Tennessee, Texas, Virginia, Washington, and Wisconsin.

\subsection{Survey Results}

The survey results indicated that a very large majority of the utility companies ( $89 \%$ ) have a GIS database; 86 percent has computerized asset management; and they collectively store different types of information which are graphically shown in Figure 2. It can be observed in this figure that 90 percent of the companies surveyed record the date of utility installation onto their GIS database, and 80 percent of them maintain information on the content of their utility lines. The type of material composing the utility asset and the depth of the utility comes next with 77 percent each. Nearly two-thirds (65\%) of the responding companies retain spatial information ( $x, y, z$ coordinates), and just over one-third (36\%) keep track of the next date of maintenance for the assets. Lastly, 


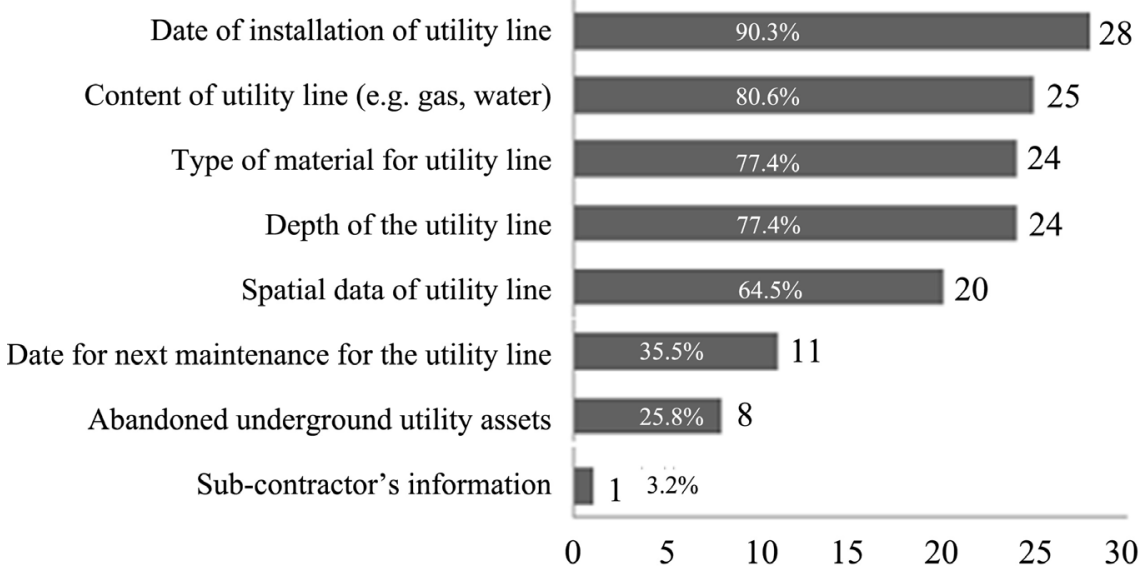

Figure 2. Asset information stored in the databases.

26 percent of the companies indicated that they had information on the abandoned utilities in their database; only one single utility provider (3\%) referred to keeping information on the subcontractors. Survey results revealed that information in the databases may be updated at varying frequencies, with 13 percent of the respondents declaring updates being done during asset maintenance, 29 percent saying daily, and 58 percent indicating monthly.

Figure 3 contains information on the utilization of $2 \mathrm{D}$ plans vs. 3D BIM models by the utility providers. According to the data displayed, 48 percent of the firms worked with $2 \mathrm{D}$ as-built plans before they adopted a GIS database, this percentage increased to 52 once they started operating a GIS database. A modest fraction (19\%) of the respondents disclosed that they currently use 3D BIM models for managing their subsurface utility information. According to survey responses, companies that have adopted BIM are using laser scanning/LIDAR, GPR, photogrammetry, robotic detection, and image acquisition (by photos) to create their 3D BIM models. Furthermore, some respondents said that $2 \mathrm{D}$ as-built drawings were being converted to 3D BIM models of the underground utilities by their companies. It appears that the utility companies participating in the survey have the necessary information to develop a 3D BIM model; however, utility location verifications may still be needed.

In terms of the future outlook, 74 percent of the respondents from the utility firms supported the idea of using GPS to improve underground asset detection, while 62 percent acknowledged that their companies are investigating additional options for accurate detection. Over two-thirds (68\%) of the survey respondents affirmed that depth data is important and should be kept along the side of the 2D plans. RFID was selected by 29 percent of the respondents as an effective tool for improving detection accuracy.

Around 41 percent of the participants replied their companies are aware of BIM technology and they were contemplating developing a new 3D model. As far as AR and mobile app utilization is concerned, a relatively small fraction (27\%) confirmed that their companies are already implementing these technologies. 


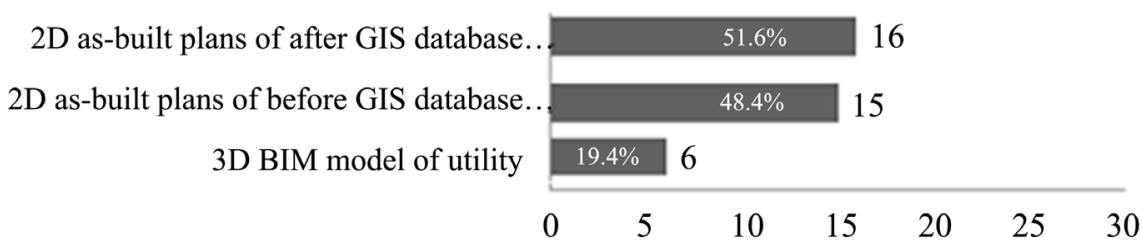

Figure 3. 2D plan vs. 3D BIM model used in the databases.

While 18 percent of the responding respondents indicated that they were planning to acquire AR, 12 percent is looking into obtaining mobile apps. The causes of excavation accidents were identified as wrong depth information (53\%), inaccurate ground marking (38\%) and human error while digging (9\%).

Turning our attention to one-call centers, evidently, every one-call utility notification center that responded to our survey has a GIS database and is storing its member polygons in it. However, a significant majority (88\%) does not verify the subsurface asset information uploaded to member polygons by the utility firms. Among the survey respondents, 63 percent opine that human error is the main cause of excavation accidents, and 37 percent think it is unsafe digging practices. The frequency of encountering abandoned underground utility lines during excavations around a marked area is characterized as "sometimes" or "rarely", implying that this may not be a substantial concern. On the question of what the utility service providers can do to improve the detection accuracy of underground utilities the top two suggestions (88\% each) were using GPS and offering excavation workshops, and the next two were 3D modeling and RFID ( $12 \%$ each). The respondents do not believe that the creation of a database will improve detection; however, they think it will help with data collection and management. A sizeable majority (62\%) of the respondents agree or strongly agree that the implementation of a BIM model will reduce the accidents and utility damages during excavation, while the remaining minority (38\%) are ambivalent (neutral) on this question. Exactly similar responses were received to the question of BIM improving detection capabilities. Interestingly, the respondents are either unsure of or against the idea of converting the member polygons to BIM models for improved operations.

Several one-call respondents commented that 3D mapping of an entire area will be daunting and very expensive. Also, the skilled personnel needed for developing a 3D BIM model may not be available in some companies. Especially, utility providers in small municipalities will most likely have limited interest in a 3D model because of the probable lack of a skilled workforce and the high costs associated with database operations.

\section{Discussion}

The state-of-the-art review coupled with the survey responses of the utility providers and one-call centers presented in this paper is clearly pointing in the direction of ongoing progress in the utility industry towards the digitalization of 
asset management practices, which are posited to ultimately benefit the operation of smart cities. The 3D BIM-GIS integration is an emerging technique that is showing promise for wide-scale adoption by the industry to create databases for underground assets that are expected to help improve overall operations and provide effective solutions for accurate utility detection and location. It is believed that this will in turn lead to fewer excavation accidents and minimize property damage saving lives and money. The technologies in terms of hardware, software, integration, and implementation know-how to accomplish this end are currently in place, and further advances are being made through continuous improvements.

Based on the findings of this research, it is possible to classify the underground utility asset management practices exercised by the US utility companies into three categories, which are described below.

- Category 1: In this management practice, existing and planned underground assets are stored in 2D as-built drawings as CAD files. GPR or other detection techniques may be used to locate the utilities; however, depth information may or may not be on the database. Typically, digital technologies such as RFID and GPS are not used.

- Category 2: The normal practice for this group of companies is that they have a GIS database holding $2 \mathrm{D}$ as-built plans and other information, but they do not have a 3D BIM model. Digital tracking techniques (e.g. GPS coordinates, RFID) are common, and 2D CAD-GIS integration is in place. Most of the firms in this category have depth and attribute data in their database; examples of the latter include, material type and content of the utility lines, spatial data (utility coordinates), installation date, abandoned utilities, and date of next maintenance (see Figure 2). Many of our respondents are employed by utility firms falling into this category, which is believed to represent the predominant practice among the US firms.

- Category 3: This group of practice regarding the management of underground utilities will invariably have a GIS database integrated with a 3D BIM model that stores appropriate attribute information. This type of system will enable integration with other technologies like AR (HoloLens) and mobile apps, and it can be viewed as the current standard of reference and the benchmark for all systems owned and operated by utility providers.

The three categories offered here expand upon and update the four cases presented by Talmaki et al. [14]. Our intent is to evaluate the systems holistically rather than focusing on just safety and damage prevention implications. It should be noted that whereas the UM study selected the best case as those utility providers which have their underground asset information in a GIS database, our study identified the best practice as storing such information in a 3D BIM model, which reflects the advancements that have taken place over the past decade.

Our study also delved into BIM-GIS integration, which supports the conver- 
sion of 2D as-built plans to 3D BIM models. Figure 4 depicts the workflow for achieving the conversion. As can be followed from this figure, the initial step in the process is to import $2 \mathrm{D}$ as-built drawings (CAD files) to the $3 \mathrm{D}$ environment, regenerating all the subsurface network data contained in the $2 \mathrm{D}$ drawings, while also updating the depth and geo-coordinate data, with subsequent verification as necessary. Note that if depth is unknown or inaccurate, further verification will be needed using geophysical exploration or other methods, subject to establishment of a tolerance zone for additional protection, which may increase cost.

In the middle step, the GIS data integration with the $3 \mathrm{D}$ model takes place. The GIS data commonly imported as a shape (.shp) file format which is a vector data file that stores the location, shape, and attributes of geographic features. It enables interoperability between the GIS and 3D modeling software. Tools such as the Autodesk Connector (or similar) software can be used for this integration, so the GIS data can be attached to the objects in the model.

The third and final step is the generation of the 3D BIM model. Once the 3D BIM model is created; an interference check with the $3 \mathrm{D}$ proximity checking criteria should be run to ensure that there are no clashes between utility line networks (e.g. pipes, structures). This feature will allow identifying physical overlapping, colliding, or intersecting of items within a specified proximity-based distance. Appropriate criteria set by the user can be used to verify the accuracy of the GIS data.

The model additionally provides details on the currently available software and tools for technology integration. Our model conceptually follows the previously described framework established by Cheng and Deng [35]. The advantage of our model representing the process for $2 \mathrm{D}$ - 3D conversion is that the desired integration can be accomplished by packaging commercially available software without any need for writing customized codes. Given the recent developments with new BIM-compatible software such as Infraworks, Civil 3D, Map 3D, and others, it is now possible to establish interoperability in a relatively less complicated manner.

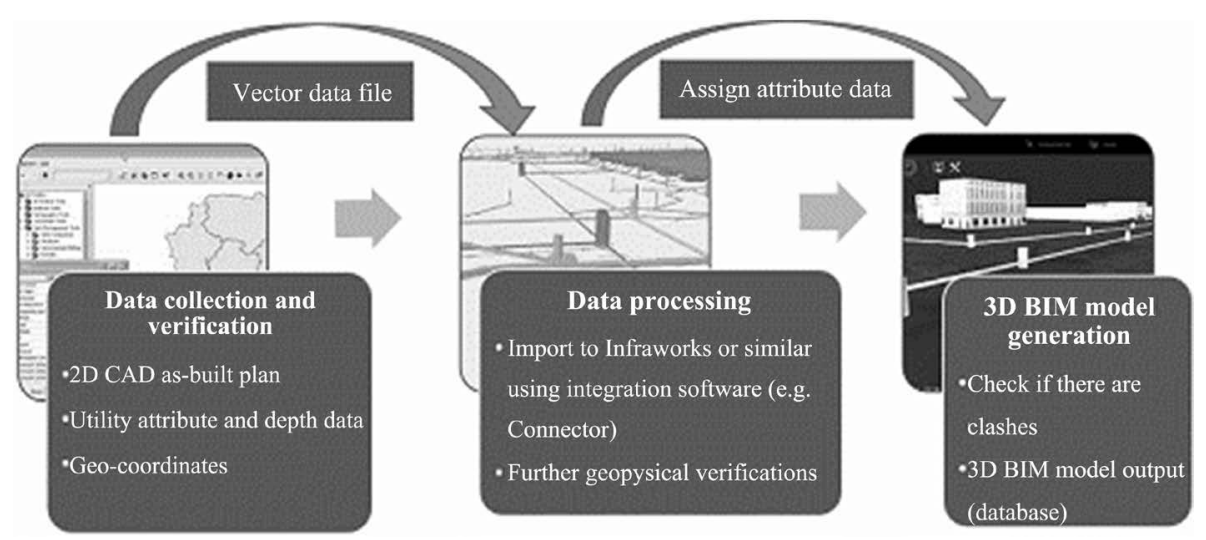

Figure 4. Proposed 2D to 3D conversion process model. 


\section{Summary and Conclusions}

The research study presented in this paper had two primary components. The first component was a comprehensive review of the state-of-the-art information drawn from literature and internet sources, as well as informal personal contacts. The second was conducting a survey of the utility industry and the notification centers to elicit practical information on how underground utilities were installed, operated and managed; what types of problems and challenges were encountered; and to what extent and how digital technologies were integrated into their subsurface asset management systems. Based on the synthesis of all the information complied through these pursuits, the following conclusions are warranted:

- Considerable advancements have been made in the detection, maintenance, and management of underground infrastructure and utilities, and the technologies needed for safe and efficient operations are currently in place.

- Digital technologies such as GIS, GPS, barcodes, VR/AR, IoT, BIM and integration software are making a favorable impact on design, construction and information management; however, there are limitations on their wide-spread adoption by the utility industry because of the insufficient digital literacy of personnel and relatively high costs of technology acquisition and implementation.

- The extent of technology integration into underground utility management varies considerably between the utility service providers. Although GIS has mostly become the norm, a great majority of the firms have not acquired the 3D BIM technology that can improve visualization while lending itself to a smart database (for reasons described above). One-call centers mostly recognize the advantages of BIM adoption, however they appear to have limited interest in embracing this technology themselves at the present time.

This research has shown and documented that converting $2 \mathrm{D}$ as-built plans to 3D BIM models is feasible in terms of know-how, hardware and software. With continuing research and development taking place in this field, it is expected that its affordability will improve over time. It is also believed that continuing education and training in digital technologies will help overcome the current literacy gap, broadening and diversifying applications.

\section{Acknowledgements}

We gratefully acknowledge the valuable contributions of Mr. Bruce Campbell and Ms. Laura Arnold from MISSDIG to this study, and extend our thanks to Dr. Joseph Vaglica, PE from Gateway Engineering and Surveying, Inc. for his guidance and support.

\section{Conflicts of Interest}

The authors declare no conflicts of interest regarding the publication of this paper. 


\section{References}

[1] Fenais, A., Ariaratnam, S.T., Ayer, S.K. and Smilovsky, N. (2019) Integrating Geographic Information Systems and Augmented Reality for Mapping Underground Utilities. Infrastructures, 4, 60. https://doi.org/10.3390/infrastructures4040060

[2] Quiroga, C., Anspach, J., Scott, P. and Kraus, E. (2018) Feasibility of Mapping and Marking. No. FHWA-HRT-16-019, Underground Utilities by State Transportation Departments.

https://www.fhwa.dot.gov/publications/research/infrastructure/pavements/16019.p df

[3] Zeiss, G. (2019) Sharing Information about the Location of Underground Utilities. https://www.linkedin.com/pulse/sharing-information-location-underground-utilitie s-geoff-zeiss/

[4] Mohanty, S.P., Choppali, U. and Kougianos, E. (2016) Everything You Wanted to Know about Smart Cities: The Internet of Things Is the Backbone. IEEE Consumer Electronics Magazine, 5, 60-70. https://doi.org/10.1109/MCE.2016.2556879

[5] Patel, K.K. and Patel, S.M. (2016) Internet of Things-IOT: Definition, Characteristics, Architecture, Enabling Technologies, Application \& Future Challenges. International Journal of Engineering Science and Computing, 6, 6122-6131.

[6] Routematch (2020) Top 10 Smart Cities in the U.S. https://www.routematch.com/top-10-smart-cities-us/

[7] MISSDIG (2002) 5 Steps to Safe Digging. https://www.missdig.org/education/5-steps-to-safe-digging.html

[8] American Public Work Association (2020) Uniform Color Code. https://www.apwa.net/Library/Resources/Uniform-Color-Code.pdf

[9] Common Ground Alliance (2020) CGA Annual DIRT for 2019 Analysis and Recommendations.

https://commongroundalliance.com/Portals/0/Library/2020/DIRT\%20Reports/2019 \%20DIRT\%20Report\%20FINAL.pdf

[10] Narain, A. (2019) What Are Various Technologies to Map Subsurface Infrastructure?

https://www.geospatialworld.net/article/technologies-to-map-subsurface-infrastruct $\underline{\text { ure }}$

[11] Al-Bayati, A.J. and Panzer, L. (2020) Reducing Damages to Underground Utilities: Importance of Stakeholders' Behaviors. Journal of Construction Engineering and Management, 146, Article ID: 04020107. https://doi.org/10.1061/(ASCE)CO.1943-7862.0001899

[12] Tuttman, M. (2018) Excavation Damage to Underground Utilities-Expert Article. https://www.robsonforensic.com/articles/underground-utilities-expert-witness/

[13] Zeiss, G. (2018) Geography 2050: Accurate Location Information about Underground Infrastructure Is Essential for Powering Our Future Planet.

https://www.Linkedin.com/pulse/geography2050-accurate-location-information-ess ential-geoff-zeiss/

[14] Talmaki, S.A., Dong, S.Y. and Kamat, V.R. (2010) Geospatial Databases and Augmented Reality Visualization for Improving Safety in Urban Excavation Operations. Proceedings of the Construction Research Congress. Innovation for Reshaping Construction Practice, Alberta, May 2010, 91-101.

https://doi.org/10.1061/41109(373)10 
[15] Read, G.F. and Vickridge, I. (1996) 10-Repair and Renovation. In: Read, G.F. and Vickridge, I.G., Eds., Sewers, Butterworth-Heinemann, Oxford, 204-232. https://doi.org/10.1016/B978-034054472-3/50013-1

[16] Goodman, J. (2019) Tech 101: Digital Twins. https://www.constructiondive.com/news/tech-101-digital-twins/561117/

[17] Fuller, A., Fan, Z., Day, C. and Barlow, C. (2020) Digital Twin: Enabling Technologies, Challenges, and Open Research. IEEE Access, 8, 108952-108971. https://doi.org/10.1109/ACCESS.2020.2998358

[18] Swenson, K. (2017) What Is Reality Capture? https://www.autodesk.com/redshift/what-is-reality-capture/

[19] The Michigan Engineering News Center (2014) Avoiding Buried Utilities and excavation Accidents.

https://news.engin.umich.edu/2014/11/avoiding-buried-utilities-and-excavation-acc idents/

[20] Wu, Y. and Kim, H. (2004) Digital Imaging in Assessment of Construction Project Progress. Proceedings of the 21 st International Symposium on Automation and Robotics in Construction, Korean Institute of Construction Technology, Jeju, September 2004, 537-542. https://doi.org/10.22260/ISARC2004/0093

[21] Saeed, N., Alouini, M.S. and Al-Naffouri, T.Y. (2019) Toward the Internet of Underground Things: A Systematic Survey. IEEE Communications Surveys \& Tutorials, 21, 3443-3466. https://doi.org/10.1109/COMST.2019.2934365

[22] Andrews, C. (2019) 5 Myths and 5 Realities of BIM-GIS Integration. https://www.esri.com/arcgis-blog/products/arcgis-pro/3d-gis/5-myths-5-realities-bi $\underline{\text { m-gis-integration/ }}$

[23] American Barcode and RFID (2020) What is RFID and How Does RFID Work. https://www.abr.com/what-is-rfid-how-does-rfid-work/

[24] Pontius, N. (2020) What Is a QR Code? https://www.camcode.com/asset-tags/what-is-a-qr-code/

[25] El-Rabbany, A. (2002) Introduction to GPS: The Global Positioning System. Artech House, Norwood.

[26] Duffy, D.P. (2017) Machine Control and GPS-Key to Efficient Site Operations. https://www.gxcontractor.com/equipment/article/13030274/machine-control-and-g pskey-to-efficient-site-operations

[27] Ellis, G. (2018) Location, Location: 4 Reasons Why GPS in Construction Matters. https://blog.plangrid.com/2018/03/location-location-4-reasons-why-gps-constructi on-matters/

[28] Lorek, S. (2018) What is BIM (Building Information Modeling)? https://constructible.trimble.com/construction-industry/what-is-bim-building-infor mation-modeling

[29] Woodward, C., Hakkarainen, M., Korkalo, O., Kantonen, T., Aittala, M., Rainio, K. and Kähkönen, K. (2010) Mixed Reality for Mobile Construction Site Visualization and Communication. Proceedings of the 10 th International Conference on Construction Applications of Virtual Reality, Sendai, November 2010, 4-5.

[30] Omar, H.S. and Dulaimi, M.F. (2015) Using BIM to Automate Construction Site Activities. Building Information Modeling in Design, Construction, and Operations, 149, 45-58. https://doi.org/10.2495/BIM150051

[31] Yan, J., Jaw, S.W., Soon, K.H. and Schrotter, G. (2019) The Ladm-Based 3d Under- 
ground Utility Mapping: Case Study. The International Archives of the Photogrammetry, Remote Sensing and Spatial Information Sciences, XLII-4/W15, 117-122. https://doi.org/10.5194/isprs-archives-XLII-4-W15-117-2019

[32] Fosu, R., Suprabhas, K., Rathore, Z. and Cory, C. (2015) Integration of Building Information Modeling (BIM) and Geographic Information Systems (GIS)-A literature Review and Future Needs. Proceedings of the 32nd CIB W78 Conference, Eindhoven, October 2015, 27-29.

[33] Song, Y.Z., Wang, X.Y., Tan, Y., Wu, P., Sutrisna, M., Cheng, J.C.P. and Hampson, K. (2017) Trends and Opportunities of BIM-GIS Integration in the Architecture, Engineering and Construction Industry: A Review from a Spatio-Temporal Statistical Perspective. ISPRS International Journal of Geo-Information, 6, 397. https://doi.org/10.3390/ijgi6120397

[34] Rosario, B. (2019) BIM \& GIS Integration: Smarter Designs, Better Outcomes. https://blogs.autodesk.com/infrastructure-reimagined/bim-gis-integration-smarterdesigns-better-outcomes/

[35] Cheng, J.C.P. and Deng, Y.C. (2015) An Integrated BIM-GIS Framework for Utility Information Management and Analyses. Proceedings of the 2015 International Workshop on Computing in Civil Engineering, Austin, 21-23 June 2015, 667-674. https://doi.org/10.1061/9780784479247.083

[36] Tawelian, L.R. and Mickovski, S.B. (2016) The Implementation of Geotechnical Data into the BIM Process. Procedia Engineering, 143, 734-741.

https://doi.org/10.1016/j.proeng.2016.06.115 


\section{Appendix}

Table A1. Survey questions for utility industry.

\begin{tabular}{ll}
\hline & Survey questions for utility industry \\
\hline Questions & Response choices
\end{tabular}

Does your organization have an asset management system?

Yes No

Does your organization utilize computerized record keeping and data management procedures for underground utility assets?

Yes No

Does your organization have a GIS map/database for its service area?

Yes No

Date of installation of utility line Content of utility line (e.g. gas, water)

Type of material for utility line

Depth of the utility line

Geometry of utility line

Date for next maintenance for the utility line

Abandoned underground utility assets

Sub-contractor information

During maintenance

If your organization has a GIS database, how frequently is it updated?

Daily

Monthly

2D as-built plans with GIS database

2D as-built plans without GIS database

Intelligent 3D model of utility

apply.

Does your company store information in an intelligent 3D (BIM Model) form?

Yes No

If your company has an intelligent 3D model for existing underground assets, did you require geophysical mapping?

If yes, what mapping technique was used to generate your $3 \mathrm{D}$ model?

If you do not currently have a $3 \mathrm{D}$ model, is your organization considering developing one?

Yes No

Textual comments

Yes No

Does your company utilize augmented reality (AR) for site visual representation of the utility assets?

Yes No

Does your company use any mobile apps for onsite visualization?

Yes No

GPS

What measures are being currently taken by your organization to improve your utility detection operations? Please check all that apply.

Keep depth information alongside your 2D drawings Adopt more accurate detection equipment

Create a 3D model

Use RFID Technology

Wrong depth information

Inaccurate ground marking

Human error during digging

Table A2. Survey questions for one-call centers.

\begin{tabular}{lcl}
\hline \multicolumn{1}{c}{ Survey questions for one-call centers } & Response choices \\
\hline What is the major cause of underground utility damages recorded during excavation? & $\begin{array}{l}\text { Not following safe digging practices } \\
\text { Human error during digging }\end{array}$ \\
\hline
\end{tabular}




\section{Continued}

How often, do you think, are abandoned underground utilities found during the excavation of a marked area?

Does your agency have a GIS map/database?

What type of information is stored in your organization's GIS map/database? Please check all that apply.

Do you verify the utility asset maps (member polygons) uploaded by the utility firms?

In your opinion, did the creation of your organization's GIS map/database improve the depth information of utilities?

Do you think a 3D BIM model for underground utilities will reduce the utility damages during excavation?

In your opinion, what can utility service providers do to improve the detection of underground utilities? Please check all that apply

Will your organization consider converting the member polygons to BIM models for improved operations?

In your opinion, what will be a/the setback(s) for adopting only the 3D BIM model for utility asset management?

How often, do you think, are abandoned underground utilities found during the excavation of a marked area?
Rarely

Sometimes

Always

Yes No

Utility member polygon Abandoned underground utilities Members' 2D as-built drawings Utility centerline information

Yes No

Yes No

Strongly Disagree

Disagree

Neutral

Agree

Strongly Agree

Encourage more equipment

Encourage utility companies to use GPS

Organize excavation safety workshops and seminars Encourage utility companies to use 3D modeling Encourage utility companies to use RFID technology

Yes No

Textual comment

Rarely

Sometimes

Always 